\title{
Time to death predictors of HIV/AIDS infected patients on antiretroviral therapy in Ethiopia
}

\author{
Melaku Tadege*
}

\begin{abstract}
Objective: The purpose of this study was to identify the major risk factors, which contributed to shortened survival time to death of HIV patients on antiretroviral therapy. Six-hundred HIV patients were included from two hospitals and six health centers record from January 2003 to December 2017. Kaplan-Meier and Cox proportional hazard model were implemented.

Results: From the Kaplan-Meier, log-rank test result indicated that there was a significant difference between tuberculosis comorbidity $(P=.000)$, occupation $(P=.027)$, and WHO clinical stage $(P=.012)$ on the survival experience of patients at 5\% statistical significance level. From the Cox regression result, the risk of death for patients who lived with tuberculosis was about 2.872-fold times higher than those patients who were negative. Most of the HIV/AIDS patients on antiretroviral therapy were died in a short period due to tuberculosis comorbidity, began with lower amount of CD4, being underweight, merchant, and being on WHO clinical stage IV.
\end{abstract}

Keywords: HIV, ART, TB, Survival

\section{Introduction}

Human immunodeficiency virus is a cause of reducing a person's ability to fight infection by reducing CD4 cell which is responsible for the body's immune response to infectious agents [1]. Human immunodeficiency virus is a public health problem globally. In 2013, the United Nations program on HIV/AIDS documented that there were about 35.3 million individuals living with HIV/ AIDS [2]. Nearly two million People were died because of AIDS-associated causes worldwide, $70 \%$ occurred in subSaharan Africa [3]. HIV incidence accounted for around $70 \%$ of all new HIV infections [4].

Sub-Saharan Africa is one of the most affected parts of the world with about 22.9 million people living with HIV AIDS and 1.2 million deaths from AIDS among children and adults in 2010 [5]. In Ethiopia, approximate to one million people are living with HIV which become the leading cause of mortality among $15-49$ years of age, that

*Correspondence: melakutadege@yahoo.com

Department of Statistics, Injibara University, Injibara, Amhara, Ethiopia accounts for about $43 \%$ of all population death in 2008 [6]. The previous study in 2012 estimated that Ethiopia is one of the most affected parts of sub-Saharan African countries by HIV and there were 41,444 deaths because of HIV/AIDS from 2011 to 2016 [7]. The previous studies discussed that discontinue ART will contribute to the death incidence of patients [8].

The approximate total 114,690 Ethiopian's died of AIDS-related conditions and this increased the number of children who lost their parents due to HIV/AIDS. As a result, this figure will also increase infant mortality rate and affect the population size in Ethiopia. In addition to mortality, the HIV/AIDS disease in Ethiopia has decreased the country's developmental growth. HIV/ AIDS is influencing every sector. This evaluation will be below the reality estimation because it is difficult to get the exact figure of death and incidence rate in the country, Ethiopia [9].

There were statements which explained that there was HIV improvement in Ethiopia even though there are a lot of people living with HIV/AIDS, death prevalence, and 
the economic effect in the country level are increasing. Some hospital based survey showed that several patients live with HIV and its mortality was high in Illubabor and Buno Bedele Zones. To this effect, the objective of this study was to determine predictors which contributed to shortened survival time to death of HIV/AIDS patients.

\section{Main text \\ Methods \\ Study area and period}

Illubabor and Buno Bedele Zones are parts of Oromia Regional State placed in the Southwest part of Ethiopia which is $600 \mathrm{~km}$ far from Addis Ababa and a well known place for coffee production, evergreen forest and a variety of tourist attractions such as rivers. Based on the 2007 census conducted by the central statistical agency, the two Zones have a total population of $1,271,609$. The study was run from January 2003 to December 2017. This study was covered six health providing centers and two senior hospitals from Illubabor and Buno Bedele Zones.

\section{Design of study}

The retrospective cohort study design was applied on patients with HIV/AIDS on ART services in six HIV/ AIDS health centers and two senior hospitals of Illubabor and Buno Bedele Zones from 2003 to 2017.

\section{Study population}

All adult HIV/AIDS patients on ART service in Ethiopia was the target population for this study and the subject population was on ART service from January 2003 to December 2017 in two senior hospitals and six health providing centers of Illubabor and Buno Bedele Zones of Oromia Region. Patients above 16 years old were covered in the study. Patients with incomplete variable of interest as well as dropout from ART were excluded.

\section{Sampling technique and procedure}

The study was applied purposive sampling technique to include the two Zones from the 21 Zones of Oromia Region. From all HIV/AIDS ART providing clinics in Illubabor and Buno Bedele Zones, eight health providers (two senior hospitals and six ART providing centers) were selected for the study. The two hospitals called Karl hospital from Illubabor and Bedele hospital from Buno Bedele Zones were included in the study. Those six health centers were selected through simple random sampling technique. Thus, one senior hospital and three health center were selected from each Zone to be included in the study. Sample selection process was explained in Fig. 1. Six hundred patients on ART from the selected clinics were included as the study population. Here each patient has a record with a distinctive identification number. The data was collected by health professionals and closely followed by the researcher throughout the entire data collection. Two data clerks did the data entry process into the statistical package of social science (SPSS) software.

\section{Study variables}

The dependent variable was time to death and divided as death (event) and censored outcomes which measured in months. Censored refers to alive. The purposes of this investigation, particularly the times for the patients who were died treated as event times and other outcomes assumed as right-censored.

The predictor variables included in the study were age, sex (male, female), marital status (married, divorced, separated, widow and never married), religion (Orthodox, Protestant, and Muslim), occupation (wife, daily labour, farmer, government worker, merchant), WHO clinical stage (I, II, III, Iv), baseline regimen type (AZT-3TC-NVP, D4t-3TC-NVP, D4t3TC-EFV, AZT-3TC-EFV), tuberculosis co-infection (positive, negative) and educational level (illiterate, primary, secondary and above secondary), CD4 level, and body weight.

\section{Data analysis}

Statistical analyses were performed using STATA version 12, statistical package of social science (SPSS) version 20 and SAS 9.2 statistical softwares (see Additional file 1). Kaplan-Meier estimators were used to display the survival experience of patient's overtime for categorical predictor variables. The log-rank test was applied to test whether there is a significant difference between predictor variables towards the survival ability of patients. Cox proportional hazard model $\left(\mathrm{h}(\mathrm{t})=\mathrm{h}_{0}(\mathrm{t}) * \exp \right.$ $\left(b_{1} x_{1}+b_{2} x_{2}+\cdots+b_{p} x_{p}\right)$ were used to identify and to check the impact of each independent variables on the time to death event. Hazard function $\mathrm{h}(\mathrm{t})$ is determined by a set of $\mathrm{p}$ covariates $\left(\mathrm{x}_{1}, \mathrm{x}_{2}, \ldots, \mathrm{x}_{\mathrm{p}}\right)$, whose impact is measured by the size of the respective coefficients $\left(b_{1}\right.$, $\left.b_{2}, \ldots, b_{p}\right)$. The term $h_{0}(t)$ is called the baseline hazard for a time to death. The proportionality assumptions of Cox model were assured on all each predictor and on the general test of proportionality. None of the predictors was failed Cox proportional hazard model required assumption (see Additional file 2). The result of Wald, Likelihood, and Score test had $\mathrm{P}(<.05)$ and the $\mathrm{R}^{2}$ adjusted residual value (.019) explained the data and the model were in a good fit. 
Total number of patients enrolled in HIV care in selected centers and Hospitals from 2003-2017

$\mathrm{N}=4,428$

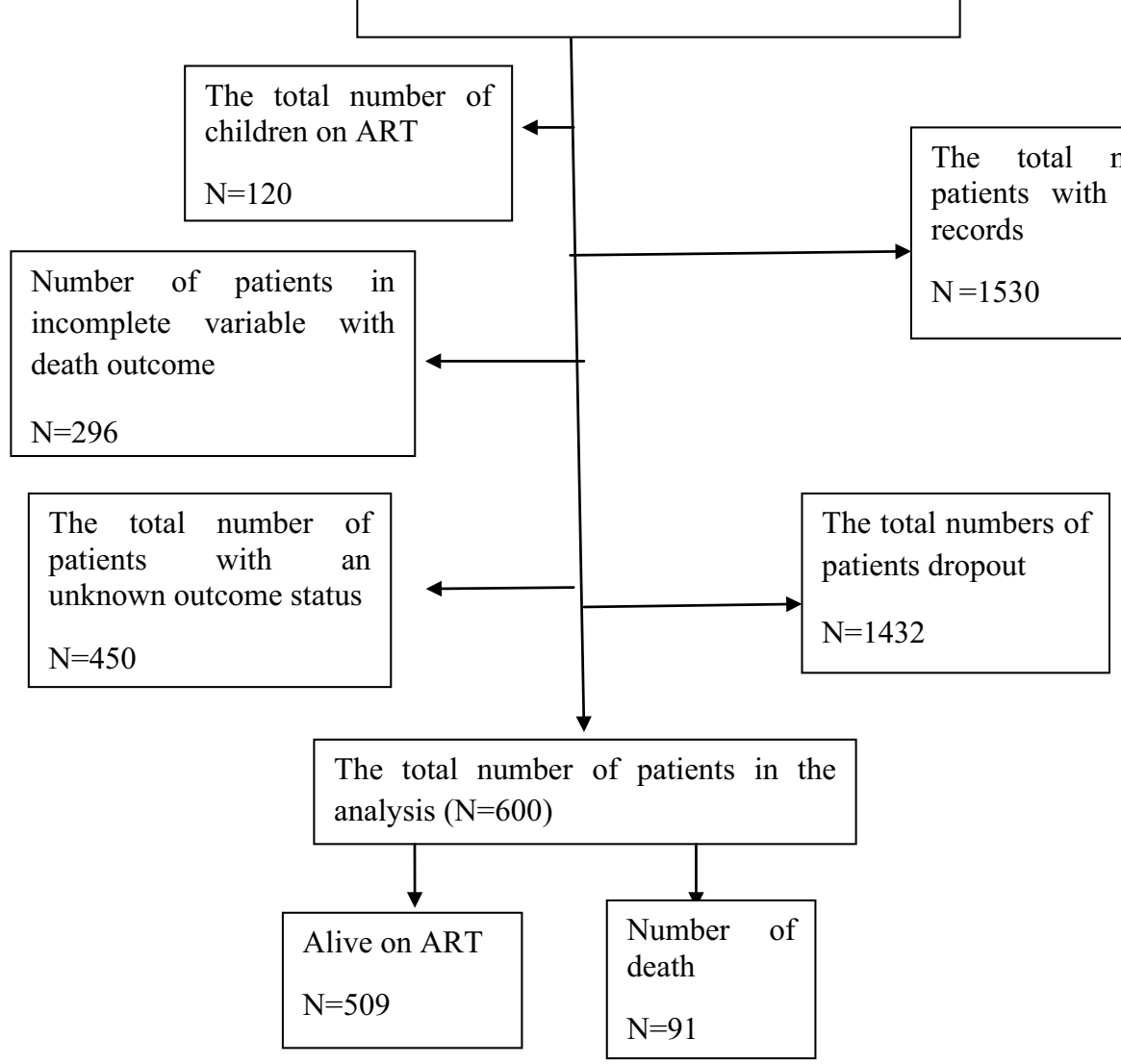

Fig. 1 Sampling procedure. Sample selection extraction (sample to be included in the study)

\section{Results}

\section{Demographic characteristics of patients}

From the total of 600 HIV patients (59.8\%) and (45.8\%) of them were female and had a primary school education level respectively. On the subject of WHO clinical stage; $(57.2 \%),(20.0 \%),(17 \%)$ and $(5.8 \%)$ of patients were stage III, II, I and IV, respectively. Regarding tuberculosis comorbidity, (19.5\%) of patients were TB positive (see Additional file 3).

\section{Chi square test of association}

There were 600 patients in the cohort study out of which $91(18 \%)$ died under antiretroviral therapy. Proportional to death for a patient who had baseline TB comorbidity were greater than those patients who were negative. Chi square test shows that death status is associated with religion, WHO clinical stage, and TB comorbidity $(\mathrm{P}<.05)$ (see Additional file 4).

\section{Comparison of the survival ability of patients}

From the Kaplan-Meier survivor estimate, merchants had shortened meantime as compared to the housewife, daily labour, the government employed and farmers. Kaplan-Meier survival estimates for the TB comorbidity group explained that TB positive had shortened mean death time as compared with TB negative. More generally from the log-rank test, there was a significant difference between TB status groups $(\mathrm{P}=.000)$, occupation $(\mathrm{P}=.027)$, religion $(\mathrm{P}=.038)$, and $\mathrm{WHO}$ clinical stage $(\mathrm{P}=.012)$ on the death time of HIV/AIDS patients on ART (Table 1).

\section{Single covariate analysis}

The relationship between each covariate and death time of HIV patients on antiretroviral therapy are presented in Table 2. As seen from this table, time to death is related to baseline CD4 level, occupation, TB status, baseline 
Table 1 Survival experience comparison

\begin{tabular}{|c|c|c|c|c|}
\hline \multirow[t]{2}{*}{ Variables } & \multirow[t]{2}{*}{ Mean time } & \multicolumn{2}{|c|}{$\begin{array}{l}95 \% \mathrm{Cl} \text { for mean } \\
\text { time }\end{array}$} & \multirow{2}{*}{$\begin{array}{l}\text { Log- } \\
\text { rank } P \\
\text { value }\end{array}$} \\
\hline & & Lower & Upper & \\
\hline \multicolumn{5}{|l|}{ Sex } \\
\hline Female & 119.112 & 114.630 & 123.593 & \multirow[t]{2}{*}{.157} \\
\hline Male & 126.618 & 119.340 & 133.896 & \\
\hline \multicolumn{5}{|l|}{ Marital status } \\
\hline Married & 114.237 & 108.919 & 119.555 & \multirow[t]{5}{*}{.675} \\
\hline Divorced & 121.684 & 110.192 & 133.177 & \\
\hline Separated & 119.538 & 111.653 & 127.422 & \\
\hline Widow & 128.734 & 116.752 & 140.716 & \\
\hline Never married & 123.394 & 110.810 & 135.978 & \\
\hline \multicolumn{5}{|l|}{ Education } \\
\hline Illiterate & 110.514 & 99.941 & 121.088 & \multirow[t]{4}{*}{.502} \\
\hline Primary school & 123.134 & 117.917 & 128.351 & \\
\hline Secondary school & 114.937 & 107.545 & 122.329 & \\
\hline Above secondary & 129.451 & 118.130 & 140.772 & \\
\hline \multicolumn{5}{|l|}{ Religion } \\
\hline Orthodox & 125.102 & 118.708 & 131.497 & \multirow[t]{3}{*}{.038} \\
\hline Protestant & 130.021 & 123.672 & 136.371 & \\
\hline Muslim & 118.465 & 110.794 & 126.137 & \\
\hline \multicolumn{5}{|l|}{ Occupation } \\
\hline Wife & 121.142 & 115.294 & 126.990 & \multirow[t]{5}{*}{.027} \\
\hline Daily labour & 113.575 & 104.588 & 122.561 & \\
\hline Farmer & 119.675 & 111.432 & 127.919 & \\
\hline Government worker & 126.332 & 116.715 & 135.948 & \\
\hline Merchant & 100.666 & 85.705 & 115.627 & \\
\hline \multicolumn{5}{|l|}{ WHO clinical stage } \\
\hline Stage I & 121.904 & 115.402 & 128.405 & \multirow[t]{4}{*}{.012} \\
\hline Stage II & 121.587 & 114.878 & 128.296 & \\
\hline Stage III & 118.618 & 112.951 & 124.284 & \\
\hline Stage IV & 123.851 & 105.592 & 142.109 & \\
\hline \multicolumn{5}{|l|}{ Original regimen } \\
\hline D4t-3TC-NVP & 118.788 & 113.000 & 124.576 & \multirow[t]{4}{*}{.726} \\
\hline D4t-3TC-EFV & 114.276 & 100.444 & 128.107 & \\
\hline AZT-3TC-NVP & 133.974 & 127.365 & 140.582 & \\
\hline AZT-3TC-EFV & 111.694 & 100.202 & 123.186 & \\
\hline \multicolumn{5}{|l|}{ Tuberculosis comorbidity } \\
\hline Positive & 97.322 & 85.538 & 109.105 & \multirow[t]{2}{*}{.000} \\
\hline Negative & 136.786 & 132.558 & 141.015 & \\
\hline
\end{tabular}

weight and WHO clinical stage at $5 \%$ of the significant level.

\section{Multi covariate analysis}

The probability of death for patients with world health organization stage one .335 times lower than those patients who were world health organization stage IV [adjusted HR $=.335$, CI (.119-.941)]. The risk of death for patients who lived in $\mathrm{TB}$ was about 2.872-fold times higher than those patients who were negative $[\mathrm{AHR}=2.872$, CI (1.870-4.409)]. When the CD4 count increased by 1 unit, the risk of death was decreased by .995 times $[\mathrm{AHR}=.995, \mathrm{CI}(.993-.998)]$. The single KG increment of weight had a power to decrease the risk of death into $4.8 \%[$ AHR $=.952$, CI (.925-.979)] (see Table 2 below).

\section{Discussion}

In this survival retrospective cohort study, there were 91 deaths from 600 patients, yielding death prevalence density are around 16 out of 100 . The independent predictors of mortality were WHO clinical stage, low weight, low CD4 count and TB co-infection. The estimated survival probability live of the cohort in 14 years were $84 \%$. This shows almost equal survival experience as compared to other studies in the Africa continent. In a Malawian cohort study, the average of the probability of being alive on antiretroviral therapy was $84 \%$ [10]. The result from this study shows patients with higher CD4 level have a smaller risk of mortality [AHR: .995 (.993.998)], which is directly related with the study [11-14]. A $1 \mathrm{~kg}$ weight increase cause to reduce mortality [AHR: .952 (.925-.979)] into 4.8\%. Another study in Malawi showed that individuals who were underweight had 6 times higher risk of dying in a short period of time [15]. Body mass index may be affected by late WHO clinical stage AIDS conditions $[16,17]$. Patients with TB comorbidity was highly associated with an increased risk of mortality [AHR: 2.872 (1.870-4.409)]. Another investigation in Uganda showed that the overall risk for death related with TB was 1.81 (95\% CI 1.24-2.65) [18]. A study in Ethiopia also explained a similar relationship [19]. Death in patients living with HIV in developing countries was linked to coexistent TB infection [20]. The study will serve for policymakers to formulate a better management of HIV/AIDS patients. Additionally, the study will be used as a baseline for further researchers or investigators.

\section{Conclusion}

In conclusion, of all the covariates, TB comorbidity, begin with a low amount of CD4, underweight, being merchant, and level of WHO clinical stage IV were found to be the most influential factor for time to death event.

\section{Limitation of the study}

This study includes only baseline variables. As a result, an investigation with time-varying covariates is recommended. Another drawback of the study was, there are a lot of patients with dropout status from treatment this 
Table 2 Single covariate and multiple covariates analysis

\begin{tabular}{|c|c|c|c|c|}
\hline \multirow[t]{2}{*}{ Variables } & \multicolumn{2}{|l|}{ Single covariates result } & \multicolumn{2}{|l|}{ Multiple covariate results } \\
\hline & Crudes HR ( $95 \% \mathrm{Cl}$ for its HR) & $\mathbf{P}$ & Adjusted HR (95\% Cl for its HR) & $\mathbf{P}$ \\
\hline \multicolumn{5}{|l|}{ Occupation } \\
\hline Wife & $.397(.206-.762)$ & $.038^{*}$ & $.381(.193-.754)$ & .078 \\
\hline Daily labour & $.609(.304-1.219)$ & & $.654(.324-1.319)$ & \\
\hline Farmer & $.346(.152-.792)$ & & $.523(.225-1.216)$ & \\
\hline Government worker & $.617(.328-1.159)$ & & $.681(.359-1.290)$ & \\
\hline \multicolumn{5}{|l|}{ Merchant } \\
\hline CD4 & $.994(.991-.997)$ & $.000^{*}$ & $.995(.993-.998)$ & $.000^{*}$ \\
\hline Weight & $.947(.921-.973)$ & $.000^{*}$ & $.952(.925-.979)$ & $.001^{*}$ \\
\hline \multicolumn{5}{|l|}{ WHO clinical stage } \\
\hline Stage I & $.321(.116-.887)$ & $.019^{*}$ & $.335(.119-.941)$ & $.023^{*}$ \\
\hline Stage II & $.448(.183-1.099)$ & & $.336(.134-.839)$ & \\
\hline Stage III & $.859(.412-1.793)$ & & $.690(.324-1.472)$ & \\
\hline \multicolumn{5}{|l|}{ Stage IV (ref) } \\
\hline \multicolumn{5}{|l|}{ TB } \\
\hline Positive & $3.439(2.269-5.213)$ & $.00^{*}$ & $2.872(1.870-4.409)$ & $.000^{*}$ \\
\hline Negative (ref) & & & & \\
\hline
\end{tabular}

AHR adjusted hazard ratio, TB tuberculosis

*Statistical significance, ref = reference category and $\mathrm{Cl}$ means confidence interval of the hazard ratio estimate

may have an impact on the study result. Consequently, an investigation with the reason behind dropout from ART is also highly appreciated.

\section{Additional files}

Additional file 1. Syntax for Cox proportional hazard model (SAS version 9.2). Cox regression model syntax in SAS.

Additional file 2. Test of proportional-hazards assumption (STATA version 12). The global test explained that proportionality assumptions were satisfied.

Additional file 3. Socio demographic characteristics of HIV patients in Illubabor and Buno Bedele Zones (SPSS version 20). The descriptive statistics explanation.

Additional file 4. Chi square test of association. Test of association between predictor variables and survival status.

\section{Abbreviations}

TB: tuberculosis; HR: hazard ratio; WHO: World Health Organization; HIV human immunodeficiency virus; AIDS: acquired immune deficiency syndrome.

\section{Authors' contributions}

This research paper is designed by MT. The author read and approved the final manuscript.

\section{Acknowledgements}

The author wishes to thank Mettu University, study participants, and data collectors for making this investigation is possible.
Competing interests

The author declare that there is no competing interest.

Availability of data and materials

If needed the raw data in excel format for this article is available.

\section{Consent for publication}

Not applicable.

\section{Ethics approval and consent to participate}

This study was reviewed and approved by the Mettu University Research Ethics Committee. As the study was based on retrospective data, informed consent was not needed.

Funding

This research was funded by Mettu University.

\section{Publisher's Note}

Springer Nature remains neutral with regard to jurisdictional claims in published maps and institutional affiliations.

Received: 19 August 2018 Accepted: 17 October 2018

Published online: 25 October 2018

\section{References}

1. Zeger SL, Diggle PJ. Semiparametric models for longitudinal data with application to CD4 cell numbers in HIV seroconverters. Biometrics. 1994:50:689-99.

2. UNAIDS. Global Health report: UNAIDS report on global AIDS epidemic. http://www.unaids.org/sites/default/files/media_asset/UNAIDS_Globa I_Report_2013_en_1.pdf.

3. UNAIDS. Report on the global AIDS epidemic 2012: joint United Nations Programme on HIV/AIDS. Geneva: Switzerland; 2012. p. 2012.

4. WHO fact sheet 2012. http://www.who.int/mediacentre/factsheets/fs360 len/index.html. 
5. Unaids J. Global report: UNAIDS report on the global AIDS epidemic 2010. Geneva: UNAIDS; 2010.

6. FMOH 2006. Annual HIV/AIDS monitoring and evaluation report in Ethiopia.

7. HAPCO. HIV/AIDS estimates and projections in Ethiopia, 2011-2016. Addis Ababa: HAPCO; 2012.

8. Kauffman GR, Elzi L, Weber R, et al. Interruption of CART limits CD4 T-cell recovery and increases the risk of opportunistic complications and death. AIDS. 2011:25(4):441-51.

9. Oromia regional state HIV/AIDS prevention office. http://www.etharc.org/ oromia/resources/kit/ARTInfotoolkit.pd.

10. Banda AC, Makombe SD, Jahn A, Tweya H, Chuka S, Yu JK, Hedt B, Ralf W, Nkhata A, Schouten EJ, Kamoto K, Harries AD. Antiretroviral therapy in the malawi defense force: access, treatment outcomes and impact on mortality. PLOS ONE. 2008;3(1):e1445.

11. Ojikutu BO, Zheng H, Walensky RP, Lu Z, Losina E, Giddy J, Kenneth AF. Predictors of mortality in patients initiating antiretroviral therapy in Durban, South Africa. S Afr Med J. 2008;98(3):204-8.

12. Sibhatu B, Ayalu AR, Tesfaye D. Predictors of mortality among HIV infected patients taking antiretroviral treatment in Ethiopia: a retrospective cohort study. AIDS Res Ther. 2012;9:15. https://doi.org/10.1186/1742-6405-9-15.

13. Johansson KA, Robberstad B, Norheim OF. Further benefits by early start of HIV treatment in low income countries: survival estimates of early versus deferred antiretroviral therapy. AIDS Res Ther. 2010;7:3.

14. McManus Hamish, O'Connor Catherine C, Boyd Mark, Broom Jennifer, Russel Darren, Watson Kerrie, Roth Norman, Read Phillip J, Petoumenos
Kathy, Law Matthew G. on Behalf of the Australian HIV observational database" Long-Term Survival in HIV positive patients with up to 15 years of antiretroviral therapy. PLoS ONE. 2012;7(11):e48839.

15. Zachariah R, Fitzgerald M, Massaquoi M, Pasulani O, Arnould L, Makombe $S$, Harries AD. Risk factors for high early mortality in patients on antiretroviral treatment in a rural district of Malawi. AIDS. 2006;20(18):2355-60.

16. Van der Sande MA, Schim van der Loeff MF, Aveika AA, Sabally S, Togun T, Sarge-Njie R, Alabi AS, Jaye A, Corrah T, Whittle HC. Body mass index at time of HIV diagnosis: a strong and independent predictor of survival. J Acquir Immune Defic Syndr. 2004;37(2):1288-94.

17. Jerene D, Naess A, Lindtjorn B. Antiretroviral therapy at a district hospital in Ethiopia prevents death and tuberculosis in a cohort of HIV patients. AIDS Res Ther. 2006;3(1):10.

18. Kigozi BK, Sumba S, Mudyope P, Namuddu B, Kalyango J, Karamagi C, Odere M, Katabira E, Mugyenyi P, Ssali F. The effect of AIDS defining conditions on immunological recovery among patients initiating antiretroviral therapy at Joint Clinical Research Centre, Uganda. AIDS Res Ther. 2009;6(17):1-10.

19. Eyuel T, Alemayehu W. Assessment of antiretroviral treatment outcome in public hospitals, South Nations Nationalities and Peoples Region, Ethiopia. Ethiop J Health Dev. 2011;25(2):102-9.

20. Canestri A, Sow PS, Vray M, Ngom F, M'boup S, Kane CT, Delaporte E, Gueye M, Peytavin G, Girard PM, Landman R. Poor efficacy and tolerability of stavudine, didanosine, and efavirenz-based regimen in treatmentnaive patients in Senegal. Med Gen Med. 2007;9(4):7.
Ready to submit your research? Choose BMC and benefit from:

- fast, convenient online submission

- thorough peer review by experienced researchers in your field

- rapid publication on acceptance

- support for research data, including large and complex data types

- gold Open Access which fosters wider collaboration and increased citations

- maximum visibility for your research: over 100M website views per year

At BMC, research is always in progress.

Learn more biomedcentral.com/submissions 